\title{
Ethanol extract of Forsythia suspensa root induces apoptosis of esophageal carcinoma cells via the mitochondrial apoptotic pathway
}

\author{
LIANMEI ZHAO ${ }^{1}$, XI YAN $^{1}$, JUAN SHI ${ }^{2}$, FENGZHI REN $^{3}$, LIHUA LIU $^{1}$, SHIPING SUN $^{1}$ and BAOEN SHAN ${ }^{1}$ \\ ${ }^{1}$ Research Center, The Fourth Hospital of Hebei Medical University, Shijiazhuang, Hebei 050011; ${ }^{2}$ National Laboratory of \\ Medical Molecular Biology, Institute of Basic Medical Sciences, Chinese Academy of Medical Sciences \\ and Peking Union Medical College, Beijing 100005; ${ }^{3}$ Department of Natural Medicine Development, \\ New Drug Research and Development Center of North China Pharmaceutical \\ Group Corporation, Shijiazhuang, Hebei 050015, P.R. China
}

Received February 3, 2014; Accepted October 2, 2014

DOI: $10.3892 / \mathrm{mmr} .2014 .2874$

\begin{abstract}
Forsythia suspensa root is used in the treatment of fever and jaundice in Traditional Chinese Medicine. In the present study, the anti-tumor activity of the ethanolic extract of Forsythia suspensa root (FSREE) against esophageal carcinoma cells was investigated in vitro and in vivo and its anti-cancer mechanism was examined. The results revealed that FSREE, rather than Forsythia suspensa ethanolic extracts from the leaf (FSLEE) and fruit (FSFEE) exhibited marked anti-tumor activity towards human esophageal cancer cells. FSREE induced cancer cell apoptosis and growth arrest by downregulating B-cell lymphoma (Bcl)-2, Bcl-extra large and myeloid cell leukemia 1, while upregulating Bcl-2-associated X protein, Bcl-2 antagonist of cell death and phorbol-12-myristate-13-acetate-induced protein 1. This led to the activation of poly(ADP ribose) polymerase, caspase- 3 and caspase- 9 , but not caspase- 8 . Furthermore, the anti-cancer activity of FSREE was associated with a decreased level of phosphorylated Janus kinase/signal transducer and activator of transcription 3 and extracellular-signal-regulated kinase signaling activity. It was also observed that the levels of cytochrome $c$ were elevated in the cytoplasm, accounting for the loss of mitochondrial membrane potential in the TE-13 cells upon treatment with FSEER. In addition, FSEER inhibited the growth of esophageal cancer cells in xenograft models and no detectable toxicity was present in the lung or
\end{abstract}

Correspondence to: Professor Baoen Shan, Research Center, The Fourth Hospital of Hebei Medical University, 12 Jiangkang Road, Shijiazhuang, Hebei 050011, P.R. China

E-mail: shanbaoen@163.com

Key words: esophageal cancer, Forsythia suspensa root, mitochondrial apoptotic pathway, B-cell lymphoma family, Janus kinase/signal transducer and activator of transcription 3, extracellular signal-regulated kinase pathway liver tissues. These observations provided further evidence of the anti-tumor effect of FSEER and may be of importance to further examine the potential role of Forsythia suspensa root as a therapeutic agent in esophageal carcinoma therapy.

\section{Introduction}

Esophageal cancer is the eighth most common type of cancer, the sixth most common cause of mortality from cancer worldwide and is more common in males (1). The incidence of esophageal cancer in the high-risk northern Chinese population exceeds 100/10,0000 and it has become a significant problem in Asian populations due to its markedly poor prognosis $(2,3)$. Although certain studies have demonstrated that the incidence of esophageal cancer is decreasing in Western countries (4), other studies have revealed that esophageal cancer has become one of the fastest-growing types of cancer in the Western world (5). Therefore, the prevalence of esophageal cancer and its poor survival rate following current therapy indicates a requirement to identify novel drugs for its treatment. The use of botanical agents or their derivatives, including isoflavone and curcumin, for the treatment of cancer has been demonstrated to be effective (6,7). Fructus forsythia, one of the most recognized Chinese medicinal herbs, has been widely used as an anti-inflammatory, diuretic, antidote and anti-cancer agent (8). Furthermore, a number of studies have revealed that an extract of Fructus forsythia fruits induces apoptosis in cancer cells, including liver, gastric and colon cancer (9), and enhances the sensitivity of cancer cells to chemotherapy (10). The root, fruit and leaf of Fructus forsythia have different medical uses. However, the plant part of Fructus forsythia with the most marked anti-tumor activity has remained to be elucidated.

In the present study, the anti-tumor activity of the root, leaf and fruit extract of Fructus forsythia was compared. Furthermore, the underlying mechanism of the anti-cancer effect of the ethanolic extract of Fructus forsythia root (FSEER) on esophageal cancer cell lines was investigated in vitro and in vivo. The ability of FSEER to inhibit the growth of esophageal cancer cells and to induce apoptosis via 
affecting levels of B-cell lymphoma (Bcl)-2 family proteins was examined. Furthermore, the effect of FSEER on Janus kinase (JNK)/signal transducer and activator of transcription (STAT) and extracellular-signal-regulated kinase (ERK) signaling pathways was investigated in vitro. In addition, the anti-tumor activity of FSEER was evaluated in vivo using a TE-13 esophageal cancer cell xenograft murine model.

\section{Materials and methods}

Reagents and antibodies. Fetal calf serum (FCS) and RPMI 1640 were purchased from Gibco-BRL (Invitrogen Life Technologies, Carlsbad, CA, USA). MTT, dimethyl sulfoxide (DMSO), RNase A and Annexin V/propidium iodide (PI) apoptosis kits were from Sigma (St. Louis, MO, USA). Monoclonal antibodies to B-cell lymphoma 2 (Bcl-2; mouse anti-rabbit; 1:1,000), Bcl-2-associated $\mathrm{X}$ protein (Bax, mouse anti-rabbit; 1:1,000) and GAPDH (rabbit anti-mouse; 1:10,000) and polyclonal antibodies to poly(ADP ribose) polymerase (PARP; sheep anti-rabbit, 1:1,000), caspase-3 (mouse anti-rabbit, 1:500), caspase-8 (sheep anti-rabbit, 1:500), caspase-9 (mouse anti-rabbit, 1:500) and cytochrome $c$ (Cyt- $c$; sheep anti-rabbit, 1:1,000) were supplied by Santa Cruz Biotechnology, Inc. (Santa Cruz, CA, USA). Polyclonal mouse anti-rabbit antibodies targeting phosphorylated (p)-ERK $(1: 1,000)$, p-Janus kinase (JAK; $1: 1,000)$ and p-signal transducers and activators of transcription (STAT)3 $(1: 1,000)$ were purchased from Cell Signaling Technology, Inc. (Danvers, MA, USA).

Tumor cell lines and culture. The esophageal cancer cell lines TE-1, TE-13 and Eca-109 were obtained from the Cellular Biology Institute of the Shanghai Academy of Sciences (Shanghai, China) and the Yes-2 cell line was contributed by Professor Tagawa Masatoshi (Chiba Cancer Center Research Institute, Chiba, Japan). The cells were maintained in RPMI-1640 medium containing 10\% FCS, $100 \mathrm{U} / \mathrm{ml}$ penicillin and $100 \mu \mathrm{g} / \mathrm{ml}$ phytomycin at $37^{\circ} \mathrm{C}$ in an incubator with a humidified atmosphere of the $5 \% \mathrm{CO}_{2}$.

Preparation of Forsythia suspensa extracts. The plant material was purchased from Le Ren Tang Pharmacy in Shijiazhuang (Hebei, China) and authenticated by Professor Fengzhi Ren (Department of Natural Medicine Development, New Drug Research and Development Center of North China Pharmaceutical Group Corporation, Shijiazhuang, China). Following drying by baking and grinding into a fine powder, the root, leaf and fruits of Forsythia suspensa were separated and (2 kg of each) was soaked in 95\% ethanol (10 liters; Sigma) under reflux for $2 \times 2 \mathrm{~h}$. The extracts were then combined and concentrated under reduced pressure at $40^{\circ} \mathrm{C}$. The ethanolic extracts of the root, leaf and fruit of Forsythia suspensa were termed FSEER, FSEEL and FSEEF, respectively. The concentrated extracts were then separated from the solid by filtration and concentrated using a rotary evaporator to obtain dry extracts. These were then dissolved in $100 \mu 1$ ethanol and resolved with $900 \mu 1$ phosphate-buffered saline (PBS) at $10 \mathrm{mg} / \mathrm{ml}$ for storage.

Cell viability assay. The viability of treated cancer cells was determined using an MTT assay. Briefly, the cells $\left(1 \times 10^{4}\right)$ were seeded into 96-well plates and cultured for $24 \mathrm{~h}$, followed by treatment with different concentrations of the extracts for a range of durations for the different experiments. A volume of $10 \mu 110 \mathrm{mg} / \mathrm{ml}$ MTT was added to each well and incubated for $3 \mathrm{~h}$ at $37^{\circ} \mathrm{C}$, following which the supernatant was removed and $150 \mu \mathrm{l}$ DMSO was added for 15-20 min. The absorbance was recorded using a microplate reader (Titertek Multiskan; Flow Laboratories, North Ryde, Australia) at a wavelength of $492 \mathrm{~nm}$. All experiments were performed in triplicate. The effect of FSREE on tumor cell viability was detected by determining the $\mathrm{IC}_{50}$ value for each cell line. The effect of each extract on the proliferation of esophageal cancer cells was calculated as the percentage of cell growth inhibition using the optical density (OD) with the following formula: Inhibitory rate $=([\mathrm{OD}$ control group - OD experiment group] / OD control group) x100\%.

Flow cytometric analysis. To investigate apoptosis, $1 \times 10^{6}$ cells were treated with FSREE $(0.25,0.5$ and $1.0 \mathrm{mg} / \mathrm{ml})$ for $48 \mathrm{~h}$ and $0.5 \mu \mathrm{g} / \mathrm{ml}$ FSREE for $0,24,48$ and $72 \mathrm{~h}$. The cells were collected and PBS was added to a final volume of $500 \mu 1$. The cells were then incubated with Annexin V-fluorescein isothiocyanate (FITC) and PI double stain according to the manufacturer's instructions and analyzed using flow cytometry with a fluorescence activated cell sorting (FACS) flow cytometer (FACSIII; Becton-Dickinson, Sunnyvale, CA, USA). Data are expressed as the mean \pm standard error of the mean of three independent experiments. For analysis of the mitochondrial membrane potential (MMP), $1 \times 10^{6}$ cells were treated with FSREE $(0.25,0.5$ and $1 \mathrm{mg} / \mathrm{ml})$ for $48 \mathrm{~h}$ and then measured by labeling the cells with $1 \mu \mathrm{m}$ rhodamine JC-1 (Molecular Probes Life Technologies, Carlsbad, CA, USA) at $37^{\circ} \mathrm{C}$ for $15 \mathrm{~min}$ and performing flow cytometric analysis.

Isolation of cellular and cytoplasmic extracts. The cellular and cytoplasmic extract proteins were obtained as previously described (11). Briefly, cells were harvested by trypsinizing and the whole cell protein was acquired by lysing the cells on ice for $20 \mathrm{~min}$ in $700 \mu \mathrm{l}$ lysis buffer with protease inhibitors and mini protease inhibitor cocktail (Roche Diagnostics, Indianapolis, IN, USA). The lysate was then centrifuged at $12,000 \mathrm{x}$ g for $20 \mathrm{~min}$ and the supernatant was collected, and stored at $-80^{\circ} \mathrm{C}$. To prepare the cytoplasmic proteins, the cell pellets were suspended in $500 \mu 1$ lysis buffer (see whole cell instructions) without Tween-20 detergent, samples were sonicated ( $1 \mathrm{sec} \times 30)$ on ice and then centrifuged at $10,000 \mathrm{x}$ g for $20 \mathrm{~min}$. The supernatant (cytoplasmic fraction) was collected in accordance with the method described in our previous report (11).

Western blot analysis. Protein levels were evaluated using bicinchoninic acid assays (Pierce Biotechnology, Rockford, IL, USA) and 12\% SDS-PAGE and were electrotransferred onto a polyvinylidene difluoride membrane (Millipore, Billerica, MA, USA). The membranes were inhibited using $5 \%$ bovine serum albumin (Sigma) for $2 \mathrm{~h}$ at room temperature and were incubated overnight at $4^{\circ} \mathrm{C}$ with the primary antibodies diluted at 1:1,000. The bound primary antibody was detected using the appropriate fluorochrome-labeled secondary anti-rabbit or mouse immunoglobulin G (IRDye 800; LI-COR Biosciences, 
Table I. Primer sequences for the reverse transcription-quantitative polymerase chain reaction.

\begin{tabular}{|c|c|c|c|}
\hline Gene & Primer sequence & Annealing temperature $\left({ }^{\circ} \mathrm{C}\right)$ & Length (base pairs) \\
\hline Noxa & $\begin{array}{l}\text { Forward: 5'-GCTGGAAGTCGAGTGTGCTAC-3' } \\
\text { Reverse: 5'-CACATTCCTCTCAATTACAATGC-3' }\end{array}$ & 55 & 211 \\
\hline Bad & $\begin{array}{l}\text { Forward: 5'-GTTCCAGATCCCAGAGTTTGAG-3 } \\
\text { Reverse: 5'-GGCGAGGAAGTCCCTTCTTA-3' }\end{array}$ & 59 & $392^{\prime}$ \\
\hline Bax & $\begin{array}{l}\text { Forward: 5'-CGGCGAATTGGAGATGAACTG-3' } \\
\text { Reverse: 5'-AGCAAAGTAGAAGAGGGCAACC-3' }\end{array}$ & 62 & 178 \\
\hline Bcl-XL & $\begin{array}{l}\text { Forward: 5'-ACTGGACTGTGGCATTGAG-3' } \\
\text { Reverse: 5'-GATTGTCGGCATACTGTTTC-3' }\end{array}$ & 55 & 312 \\
\hline $\mathrm{Bcl}-2$ & $\begin{array}{l}\text { Forward: 5'-CGACTTCGCCGAGATGTCCAGCCAG-3' } \\
\text { Reverse: 5'-ACTTGTGGCCCAGATAGGCACCCAG-3' }\end{array}$ & 55 & 252 \\
\hline Mcl-1 & $\begin{array}{l}\text { Forward: 5'-TCGAGTGATGATCCATGTTTTC-3 } \\
\text { Reverse: 5'-GATATGCCAAACCAGCTCCTAC-3' }\end{array}$ & 58 & $302^{\prime}$ \\
\hline GAPDH & $\begin{array}{l}\text { Forward: 5'-CGGATTTGGTCGTATTGGG-3' } \\
\text { Reverse: 5'-TGCTGGAAGATGGTGATGGGATT-3' }\end{array}$ & 60 & 279 \\
\hline
\end{tabular}

Noxa, phorbol-12-myristate-13-acetate-induced protein 1; Bad, Bcl-2-associated death promoter; Bax, Bcl-2-associated X protein; Bcl-2, B-cell lymphoma 2; Mcl-1, myeloid cell leukemia 1.

Lincoln, NE, USA) for $1.5 \mathrm{~h}$ at room temperature. Following washing three times with Tris-buffered saline (Sigma) and Tween 20 (Sigma) for 10 min each, the membrane was imaged using an Odyssey infrared imaging system (LI-COR Biosciences). The levels of protein were calculated as the ratio of the intensity of protein to that of GAPDH. The experiments were performed in triplicate wells and repeated three times.

Reverse transcription quantitative polymerase chain reaction (RT-qPCR) analysis. Total RNA was extracted from the treated cells using TRIzol reagent (Sigma) according to the manufacturer's instructions. RT-qPCR was conducted as previously described (11), with modifications, using RT-qPCR kits from Promega Corp. (Madison, WI, USA). In brief, cDNA was prepared using RNA samples (2 $\mu \mathrm{g})$ to which $1 \mu \mathrm{g}$ oligo(dT), $0.5 \mathrm{mM}$ deoxynucleotide triphosphate and 200 units of the Revert Aid $^{\mathrm{TM}} \mathrm{H}-$ Minus M-MuLV Reverse Transcriptase enzyme were added (MBI Fermentas, Hanover, MD, USA). RT-qPCR analysis was performed using primers synthesized by Sangon Biotech Co., Ltd (Shanghai, China), as shown in Table I, and $1 \mu \mathrm{l}$ RT product was incubated with 1 unit Taq DNA polymerase in a 20- $\mu 1$ reaction mixture (Promega Corp.). The amplified fragments were detected on a $1.5 \%(\mathrm{w} / \mathrm{v})$ agarose gel and analyzed using an IS1000 image analysis system (Alpha Innotech, San Leandro, CA, USA).

Effect of FSEER on tumor growth in vivo. Twelve Balb/c nude mice (5-6 weeks old, 18-20 g) were purchased from the Laboratory Animal Center of Hebei Medical University (Shijiazhuang, China). The procedures using animals were approved by the Animal Care and Use Committee. The Balb/c nude mice were injected subcutaneously into the right axillary fossa with TE-13 cells $\left(2 \times 10^{6} / 0.1 \mathrm{ml}\right)$. When the tumor growth reached a volume of $\sim 0.1 \mathrm{~cm}^{3}$, the mice were randomly assigned into two groups (n=6/group). The treatment group were intraperitoneally administered FSEER $(50 \mathrm{mg} / \mathrm{ml})$ and the control group was administered an equal volume of PBS once every two days for 14 days. The tumor volumes were estimated using the following formula: $0.5 \mathrm{x}$ length $\mathrm{x}$ width $^{2}$, for which the length and perpendicular width were measured using calipers. Subsequently, the lung and liver tissues were stained for histological analysis using hematoxylin and eosin (H\&E; Invitrogen Life Technologies) under an Olympus IX-70 microscope (Olympus Corp., Melville, NY, USA) to analyze the toxicity of FSEER.

Statistical analysis. All data analysis was performed using SPSS 13.0 software (SPSS, Inc., Chicago, IL, USA). The statistical significance between values was determined by one-way analysis of variance, and the Student's t-test was used to compare two independent samples. Fisher's probability was used to analyze the difference in protein expression between groups. $\mathrm{P}<0.05$ was considered to indicate a statistically significant difference. All data are expressed as the mean \pm standard deviation. Results shown in the figures were obtained from at least three independent experiments with a similar pattern.

\section{Results}

Inhibition of cell proliferation by extracts of Forsythia suspensa. The TE-13 cells were treated with different extracts of Forsythia suspensa for $48 \mathrm{~h}$ to evaluate their anti-cancer activity. The $\mathrm{IC}_{50}$ values of FSEES, FSEER and FSEEL are shown in Table II. On TE-13 cells, the $\mathrm{IC}_{50}$ values of FSEES, FSEER and FSEEL were $4.25,0.58$ and $78 \mathrm{mg} / \mathrm{ml}$, respectively (Table II). This demonstrated that the extract of the root, rather than that of the fruit or leaf, of Forsythia suspensa had a more marked inhibitory effect on the esophageal carcinoma cells. Therefore, 
Table II. Inhibitory effect of ethanolic extract of Forsythia suspensa on esophageal cancer cells.

\begin{tabular}{lrrrr}
\hline $\begin{array}{c}\mathrm{IC}_{50} \\
(\mathrm{mgml})\end{array}$ & TE-13 & TE-1 & Eca-109 & Yes-2 \\
\hline FSEEL & 78.01 & 89.26 & 88.03 & 72.91 \\
FSEES & 4.25 & 8.92 & 10.90 & 7.82 \\
FSEER & 0.58 & 1.25 & 2.30 & 1.46 \\
\hline
\end{tabular}

Each cell line was treated with the indicated extract for $48 \mathrm{~h}$, respectively. All experiments were performed three times in triplicate. FSEEL, Forsythia suspensa ethanolic extract of the leaves; FSEES, Forsythia suspensa ethanolic extract of the stem; FSEER, Forsythia suspensa ethanolic extract of the root.

FSEER was selected to further investigate its inhibitory activity on esophageal cancer cells and the underlying mechanism. The inhibitory rates of $0.5 \mathrm{mg} / \mathrm{ml}$ FSEER against the esophageal cancer cell lines TE-13, ECA-109, TE-1 and Yes-2 were 64.8, 51.6, 49.0 and 48.0\%, respectively (Fig. 1A). Therefore, TE-13 cells were used in the subsequent experiments. Following treatment with $0.251 \mathrm{mg} / \mathrm{ml} \mathrm{FSEER} \mathrm{for} \mathrm{24,} 48$ and $72 \mathrm{~h}$, the growth of TE-13 cells was inhibited in a dose- and time-dependent manner (Fig. 1B).

FSEER induces cell apoptosis in vitro. Giemsa staining and flow cytometry were performed to investigate whether FSEER induced TE-13 cell apoptosis. As shown in Fig. 2A and B, morphological changes observed using microscopy and Giemsa staining revealed that tumor cells exhibited decreased growth, loss of volume, cytoplasm concentration, karyokinesis and deformation to a round appearance following treatment with FSEER $(0.5 \mathrm{mg} / \mathrm{ml})$ for $48 \mathrm{~h}$. However, the cells in the control group were observed to maintain a regular appearance, intensive growth and a polygonal shape. Flow cytometry was performed to estimate the rate of apoptosis by quantitative assessment of Annexin V/PI stained TE-13 cells. As shown in Fig. 2C, FSEER treatment increased the number of Annexin V-FITC-positive and PI-negative cells in a dose- and time-dependent manner compared with that in the control group. In order to determine whether FSEER-induced apoptosis of TE-13 cells was mediated through mitochondrial dysfunction, the MMP was measured using the mitochondrial-sensitive dye JC-1. As shown in Fig. 2D, the number of cells exhibiting depolarized mitochondrial membranes was significantly increased in the FSEER $(0.25,0.5,1.0 \mathrm{mg} / \mathrm{ml})$-treated cells compared with that in the control group.

Involvement of the mitochondrial signaling pathway in FSREE-induced apoptosis. Caspase-3 can be activated by a mitochondrial apoptotic pathway involving caspase-9, termed the intrinsic pathway, or by a death receptor pathway involving caspase-8, the extrinsic pathway, contributing to cell apoptosis $(12,13)$. The results of the present study revealed that treatment of TE-13 cells with FSEER for $48 \mathrm{~h}$ resulted in cleavage of caspase-3, as evidenced by the appearance of 19-kDa intermediates (Fig. 3A). Furthermore, treatment of
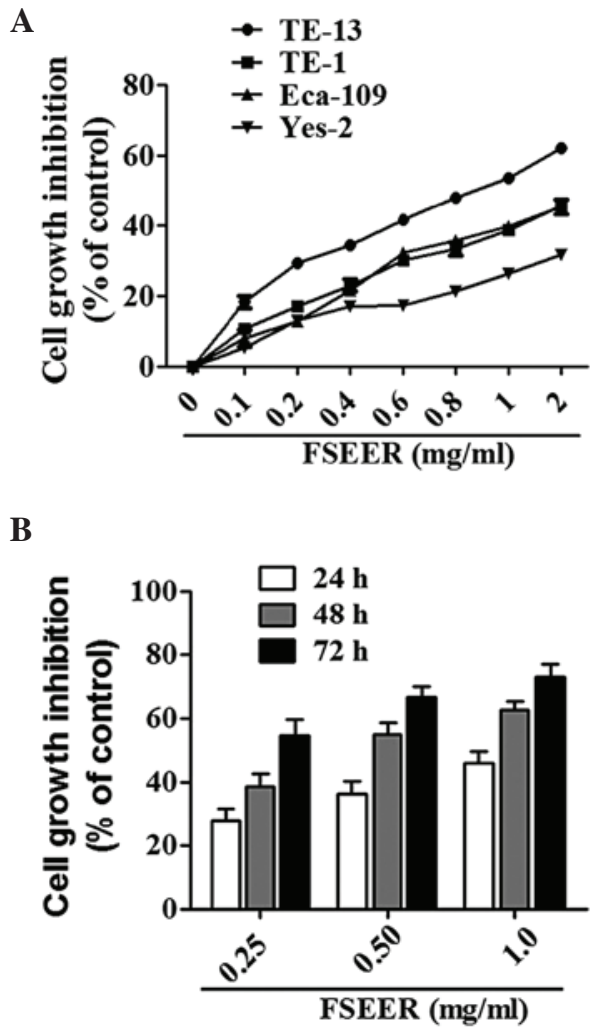

Figure 1. (A) FSEER inhibited proliferation of esophageal carcinoma cells in a dose-dependent manner following a $24 \mathrm{~h}$ treatment. (B) FSEER inhibited proliferation of esophageal carcinoma cells in a time-dependent manner. Results of the MTT assays are expressed as the mean \pm standard deviation of four wells in triplicate experiments. FSEER, Forsythia suspensa ethanolic extract of the root.

the TE-13 cells with FSEER also resulted in significantly increased cleavage of caspase- 9 without changes in procaspase-8 levels (Fig. 3B). These results suggested that FRSEE triggered apoptosis through the intrinsic pathway, but not the extrinsic pathway. Activation of caspases during apoptosis results in the cleavage of critical cellular substrates, including PARP (14). Therefore, PARP has become an essential marker of caspase-3 activity in intrinsic apoptotic pathways (15). As shown in Fig. 3A, the levels of cleaved PARP fragment, which is the active form, were significantly increased following exposure to FSREE for $48 \mathrm{~h}$, further confirming the activity of caspase-3 in the TE-13 cells. In addition, a key step in the intrinsic apoptotic pathway is the damage of mitochondria and the release of $\mathrm{Cyt}-c$ to activate apoptotic protease activating factor 1, which in turn activates the caspase cascade (16). Following treatment of TE-13 cells with FSEER, Cyt- $c$ levels increased in the cytoplasmic fraction in a dose- and timedependent manner (Fig. 3). This result indicated that FSEER induced the release of Cyt- $c$ from the mitochondria to the cytoplasm in TE-13 cells and further suggested that the mitochondrial pathway was involved in FSREE-induced apoptosis.

Members of the Bcl-2 family are involved in FSREE-induced apoptosis of TE-13 cells. Mitochondrial integrity is regulated by the Bcl-2 family, which is constituted of pro-apoptotic members, including Bcl-2, Bcl-xL and myeloid cell leukemia 1 
A

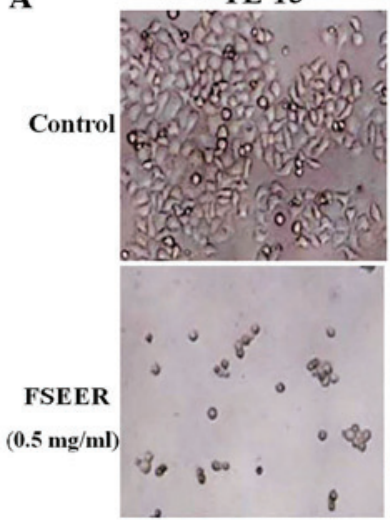

TE-1

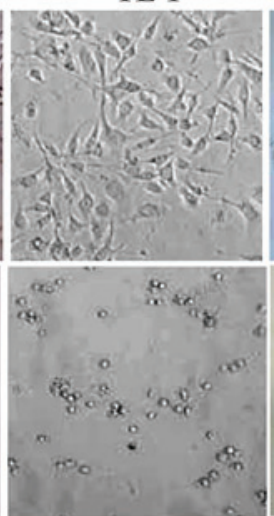

Eca-109

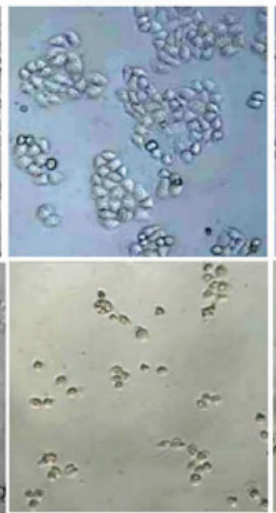

Yes-2

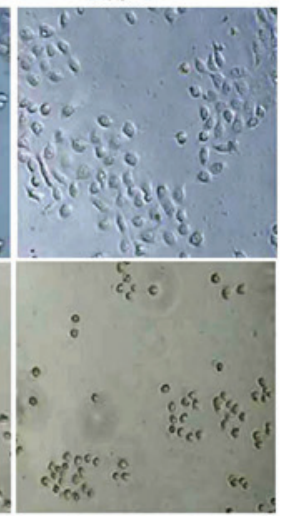

B

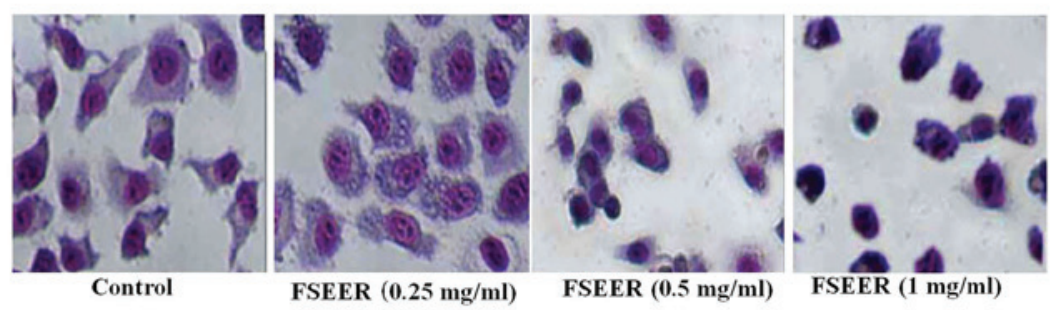

C
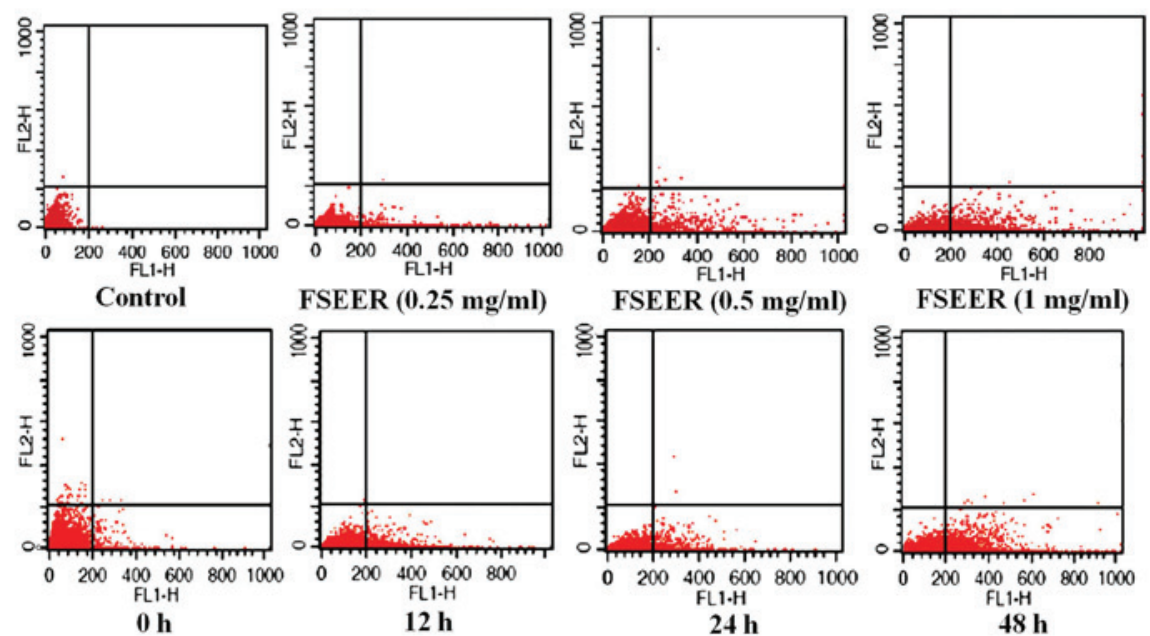

$\operatorname{FSEER}(0.5 \mathrm{mg} / \mathrm{ml})$

$\operatorname{FSEER}(1 \mathrm{mg} / \mathrm{ml})$
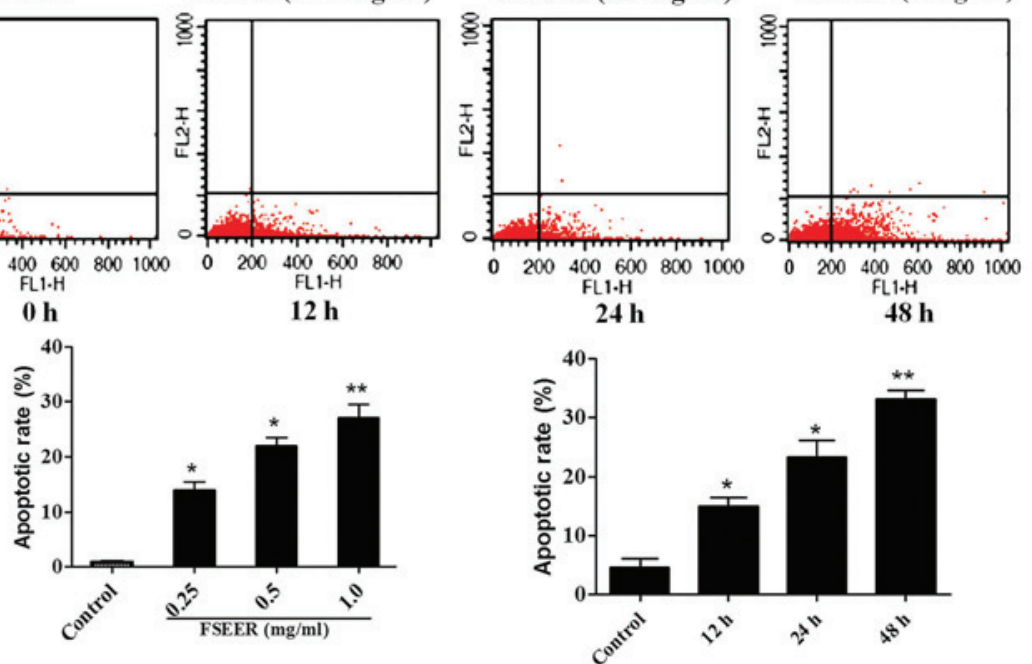

\section{D}

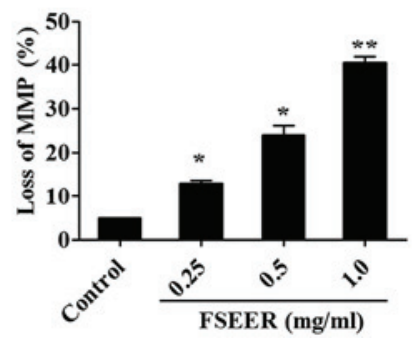

Figure 2. (A) Morphological changes of TE-13, TE-1, Eca-109 and Yes-2 cells treated with $0.5 \mathrm{mg} / \mathrm{ml}$ FSEER for 48 h. (B) TE-13 cells were treated with $0.251 \mathrm{mg} / \mathrm{ml}$ FSEER for $48 \mathrm{~h}$ and stained using Giemsa for $10 \mathrm{~min}$. (C) Effects of FSEER on the apoptotic rate of TE-13 cells following a $48 \mathrm{~h}$ treatment. Representative histograms of Annexin fluorescein isothiocyanate-stained and propidium iodide-stained cells. ${ }^{*} \mathrm{P}<0.05,{ }^{* *} \mathrm{P}<0.01$, compared with the control group. (D) Histogram demonstrating increased MMP by $0.5 \mathrm{mg} / \mathrm{ml} \mathrm{FSEER}$. ${ }^{*} \mathrm{P}<0.05,{ }^{* * *} \mathrm{P}<0.01$, compared with the control group. FSEER, Forsythia suspensa ethanolic extract of the root; MMP, mitochondrial membrane potential.

(Mcl-1), and anti-apoptotic members, including Bax, Bcl-2-associated death promoter (Bad) and phorbol-12-myristate-13-acetate-induced protein 1 (Noxa) $(17,18)$. Thus, the expression of these Bcl-2 family members was detected in TE-13 cells following treatment with various concentrations of FSREE for different periods of time. As shown in Fig. 4A and B, a decrease in the expression of Bcl-2, Bcl-xL and Mcl-1 was observed, accompanied by an increase in the expression of Bax, Bad and Noxa mRNA in the TE-13 cells following treatment with FSEER $(0.25-1 \mathrm{mg} / \mathrm{ml})$ for $24 \mathrm{~h}$ (Fig. 4A). In addition, the change in the expression levels of the above proteins was consistent with the mRNA expression in response to treatment with FSEER $(0.25-1 \mathrm{mg} / \mathrm{ml})$ for $48 \mathrm{~h}$ (Fig. 4B). These results further demonstrated that the 
A
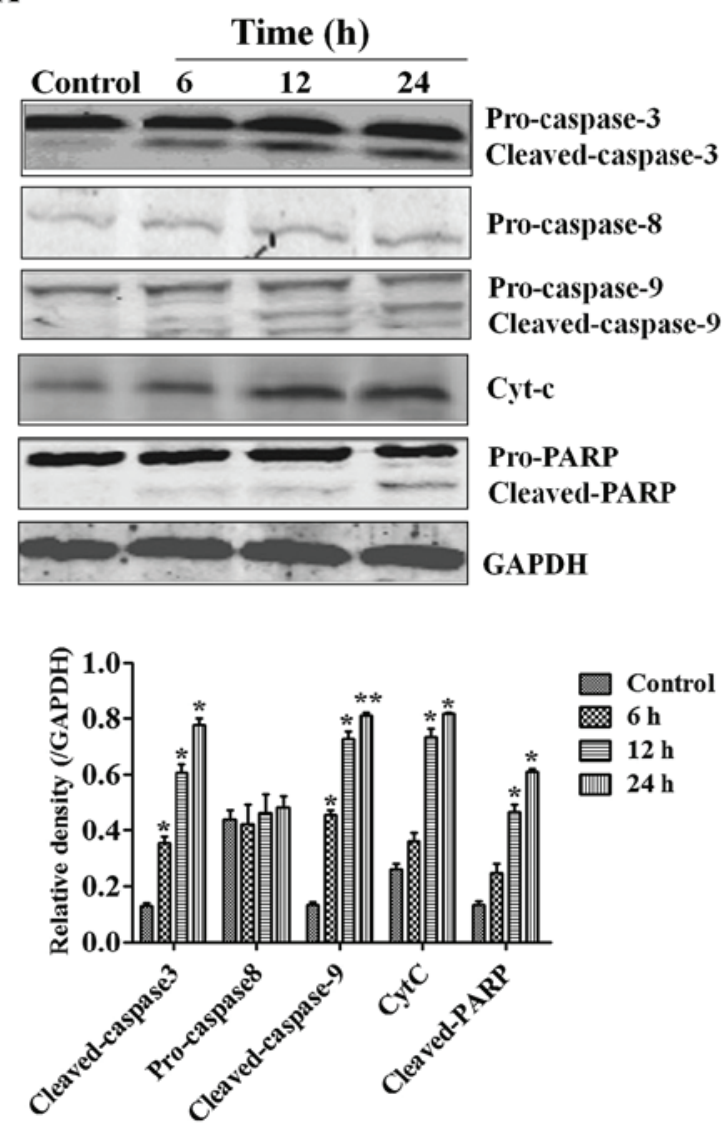

B
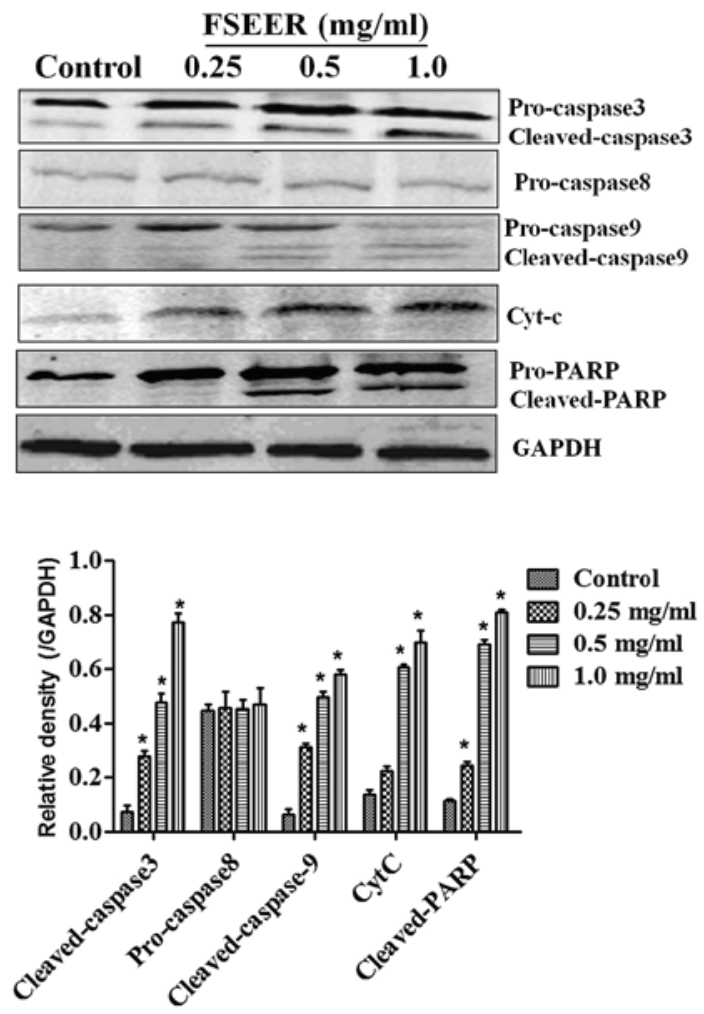

Figure 3. Western blot analysis of TE-13 cells treated with FSEER. The TE-13 cells were treated with (A) FSEER at various concentrations for $24 \mathrm{~h}$ and (B) $0.5 \mathrm{mg} / \mathrm{ml}$ FSEER for 6,12 and $24 \mathrm{~h}$. Cleaved caspase-3, caspase-9 and PARP were activated and Cyt $-c$ in the cytosolic fraction increased in a dose- and time-dependent manner. ${ }^{*} \mathrm{P}<0.05,{ }^{* * *} \mathrm{P}<0.01$, compared with the control group. FSEER, Forsythia suspensa ethanolic extract of the root; Cyt- $c$, cytochrome $c$; PARP, poly(ADP ribose) polymerase.
A

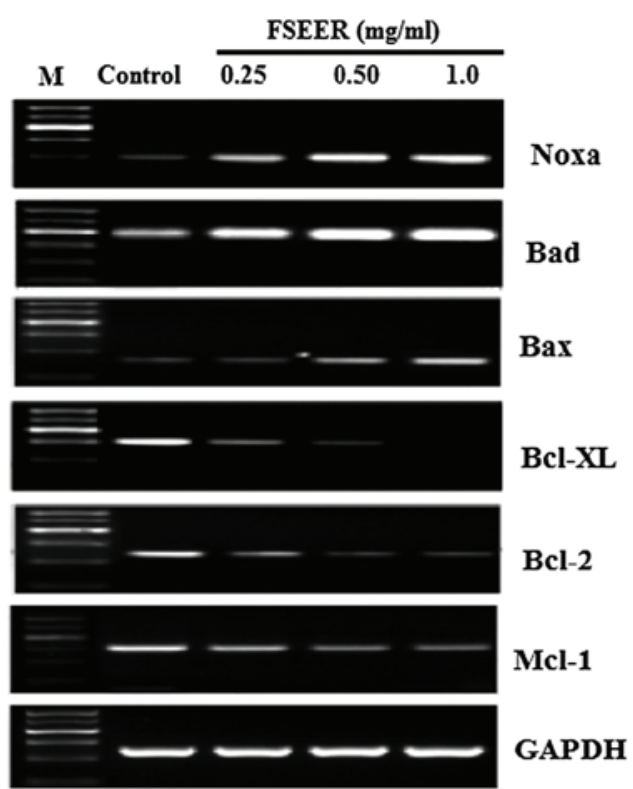

B

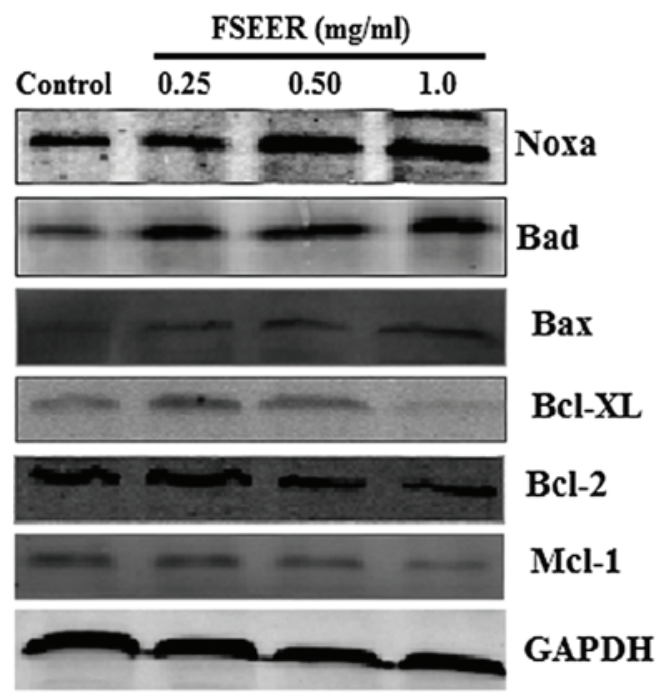

Figure 4. Reverse transcription quantitative polymerase chain reaction and western blot analysis of the protein expression of the Bcl2 family. TE-13 cells were treated with FSEER $(0.25,0.5$ and $1.0 \mathrm{mg} / \mathrm{ml})$ for $48 \mathrm{~h}$ and the (A) mRNA and (B) protein expression levels of Bcl-2, Bcl-xL, Mcl-1, Bax, Bad and Noxa were examined. FSEER, Forsythia suspensa ethanolic extract of the root; Bcl-2, B-cell lymphoma 2; Bcl-Xl, Bcl-extra large; Mcl-1, myeloid cell leukemia 1; Bax, Bcl-2-associated X protein; Bad; Bcl-2-associated death promoter; Noxa, phorbol-12-myristate-13-acetate-induced protein 1.

mitochondrial apoptotic pathway was activated by the Bcl-2 family in FSERR-induced apoptosis in esophageal cancer TE-13 cells.

Effect of FSEER on the JAK/STAT3 and ERK signaling pathways. The JAK/STAT3 and ERK signaling pathways are important pathways in cell growth and apoptosis and the inactivity of these pathways may regulate the $\mathrm{Bcl} 2$ family resulting in growth arrest and apoptosis in certain tumor cells (19-21). Several studies have suggested that anti-apoptotic genes are regulated by interleukin 6 and STAT3, including Bcl-2, Bcl-xL and Mcl-1 (22). While these genes are induced by 
A

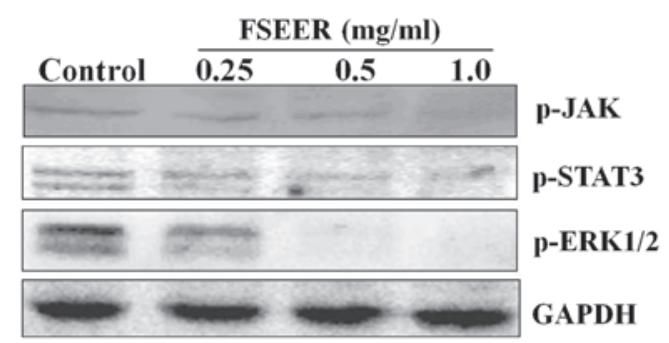

B

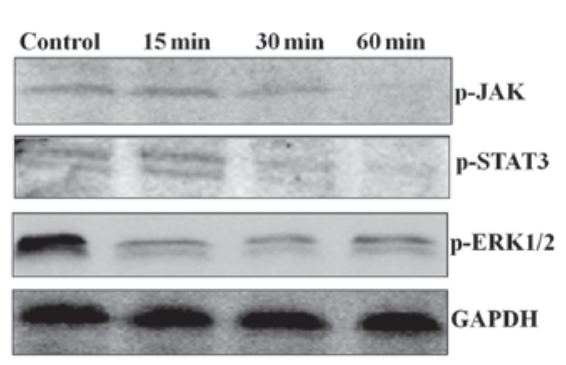

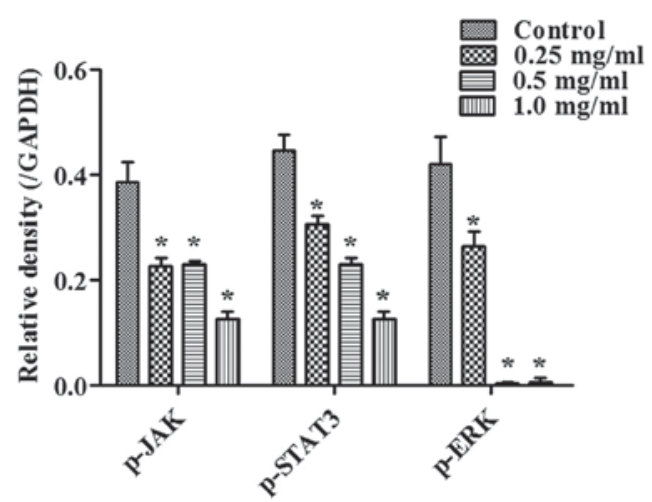

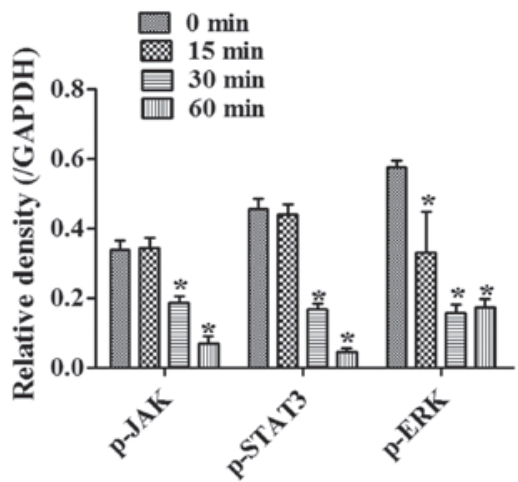

C

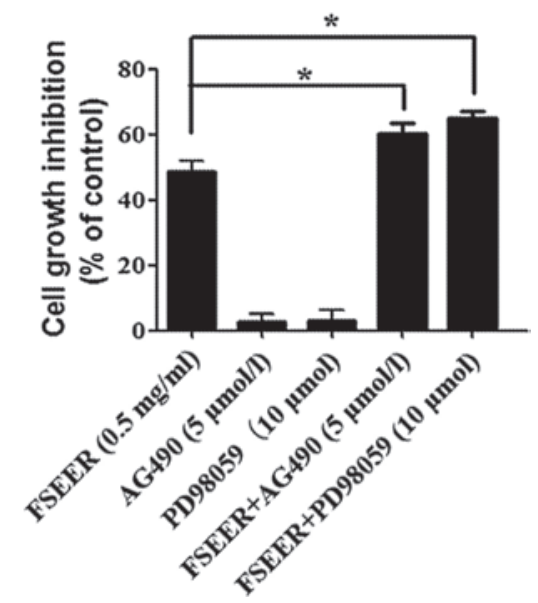

Figure 5. Inactivity of FSEER on the JAK/STAT3 and ERK signaling pathways in TE-13 cells. (A) TE-13 cells were treated with FSEER at 0.25, 0.5 and 1.0 mg/ml for $60 \mathrm{~min}$ and with (B) $0.5 \mathrm{mg} / \mathrm{ml}$ FSEER for 15, 30 and $60 \mathrm{~min}$. (C) Effects of AG490 (5 mol/1) or PD98059 (10 $\mu$ mol/1) alone or in combination with FSEER on the FSEER-mediated TE-13 cell proliferation. * $\mathrm{P}<0.05$, compared with the control group. FSEER, Forsythia suspensa ethanolic extract of the root; p-JAK, phosphorylated Janus kinase; STAT, signal transducer and activator of transcription; ERK, extracellular-signal-regulated kinase.

STAT3, the most important anti-apoptotic gene is considered to be Mcl-1 and Bcl-xL (23). The results of the present study revealed that FSEER markedly reduced the expression of p-JAK/STAT3 and p-ERK in a concentration and time-dependent manner (Fig. 5A and B), indicating that FSEER inhibited the activation of the JAK/STAT3 and ERK signaling pathways in TE-13 cells. In order to verify the involvement of these pathways in FSEER-induced apoptosis, the effect of FSEER on the proliferation of TE-13 cells was observed in the presence of an inhibitor of the signaling pathway. AG490 is a member of the typhostin family of tyrosine kinase inhibitors, which inhibit the JAK/STAT3 signaling pathway in several types of cancer cell, including esophageal carcinoma cells $(24,25)$. Beales and Ogunwobi (26) demonstrated that the
P4244 MAP kinase inhibitor PD98059 enhanced the activity of leptin-mediated esophageal adenocarcinoma cell apoptosis. The present study revealed that, although AG490 (5 $\mu \mathrm{mol} / \mathrm{l})$ and PD98059 $(10 \mu \mathrm{mol} / \mathrm{l})$ alone were not able to inhibit the proliferation of TE-13 cells, they significantly enhanced the inhibitory effect of FSEER $(0.5 \mathrm{mg} / \mathrm{ml})$ on the proliferation of TE-13 cells by $\sim 25$ and $35 \%$, respectively (Fig. 5C). Taken together, the findings of the present study demonstrated that the induction of apoptosis of TE-13 cells by FSEER was achieved through downregulation of the JAK/STAT3 and ERK signaling pathways.

Anti-tumor efficacy of FSEER in vivo. The established TE-13 cells implanted into nude mice were used as a model 
A

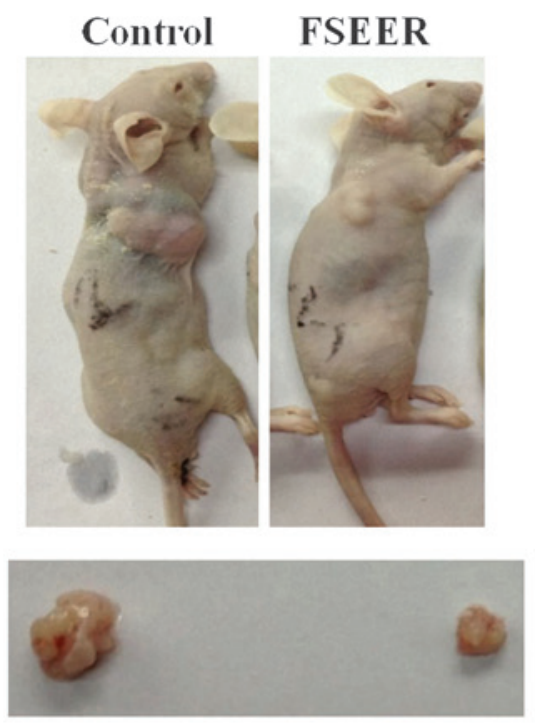

C
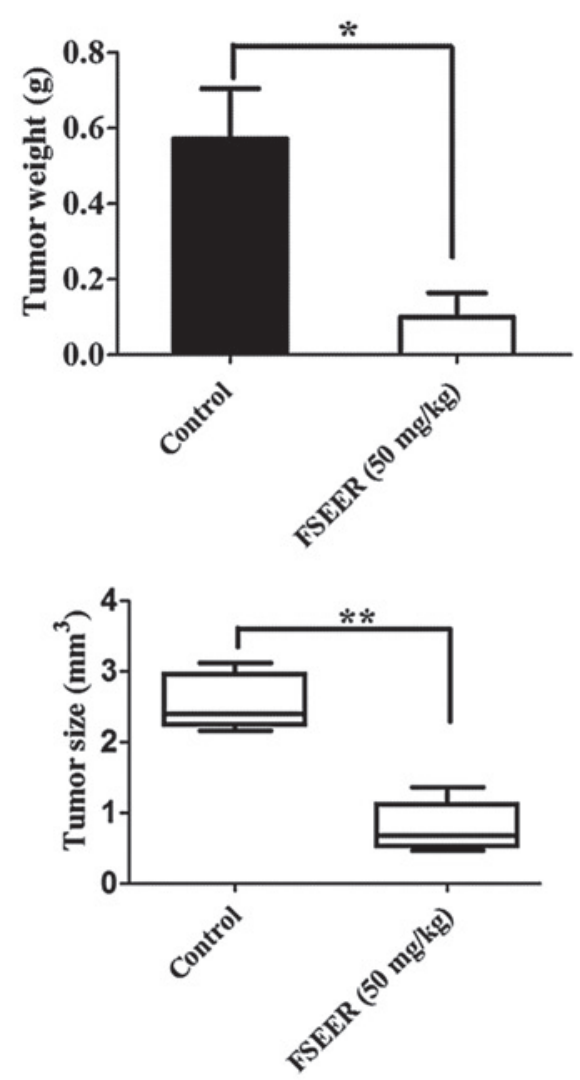

B

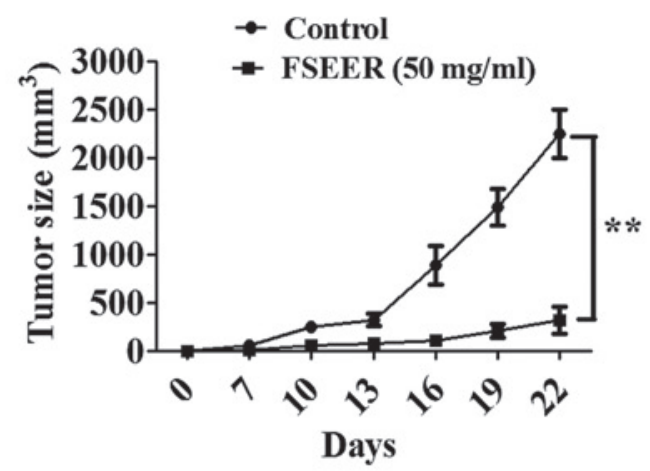

D

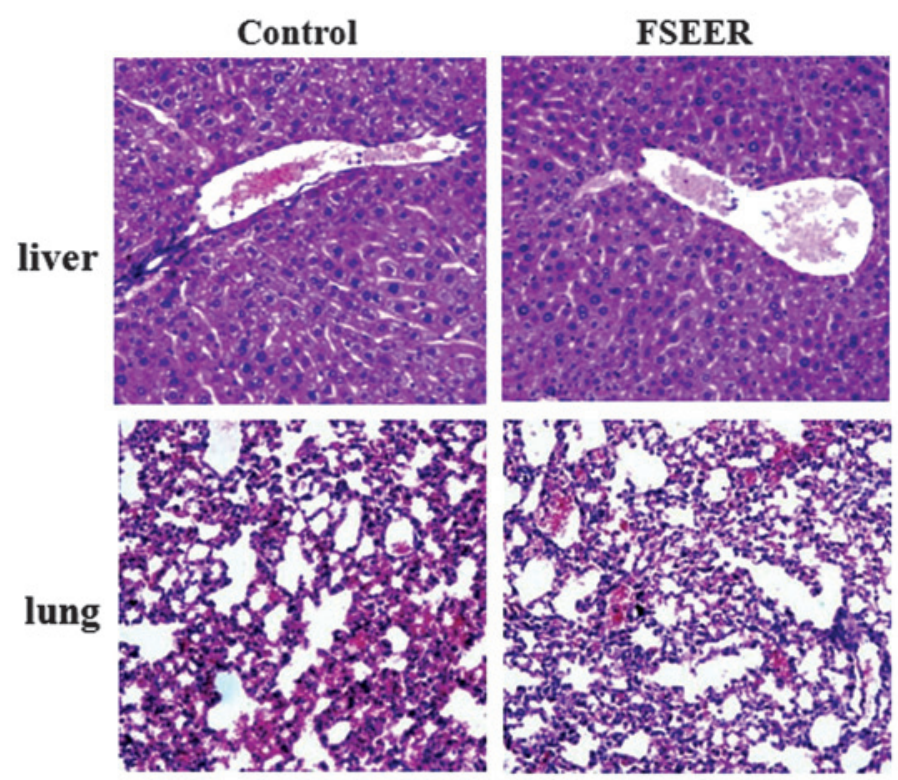

Figure 6. FSEER mediates the inhibition of tumor growth in vivo. TE13 xenograft mice were treated intraperitoneally with PBS or FSEER (50 mg/kg) once every two days for 14 days. (A) Two representative athymic nude mice from the PBS-treated and FSEER (50 mg/kg)-treated groups. (B and C) Antitumor efficacy of FSEER in the TE-13 xenograft model. Values are expressed as the mean \pm standard deviation (n=5). (D) Tissues from the liver and lung of the tumor xenograft mice were stained using hematoxylin and eosin. ${ }^{*} \mathrm{P}<0.05,{ }^{* *} \mathrm{P}<0.01$, compared with the control group. FSEER, Forsythia suspensa ethanolic extract of the root; PBS, phosphate-buffered saline.

to observe the effect of FSEER on the tumor burden in vivo. The treatment regimens were performed as described previously. As shown in Fig. 6A, compared with the control group, the FSEER-treated group demonstrated significant inhibition of tumor growth. Following treatment with FSEER for 20 days, the mean tumor volume of the treated group was $0.79+0.17 \mathrm{~cm}^{3}$ and the mean weight was $0.35+0.08 \mathrm{mg}$. These were significantly lower compared with those of the control group, which were $2.56+0.18 \mathrm{~cm}^{3}$ and $1.35+0.11 \mathrm{mg}$, respectively (Fig. 6B) Following inoculation of the TE-13 cells, a clear increase in tumor volume was observed from day 7 in the vehicle group until the animals were sacrificed. However, tumor volume in mice treated with FSEER $(50 \mathrm{mg} / \mathrm{ml})$ from the day of inoculation started to increase from day 10 and tumor volume increased slowly (Fig. 6C). Furthermore, no clear pathological changes were observed in the liver and lung in the H\&E-stained sections 
of FSEER-treated mice (Fig. 6D), indicating that FSEER had no detectable toxicity in mice. In conclusion, these results indicated that FSEER exerted anti-tumor effect in vitro and in vivo.

\section{Discussion}

Forsythia suspensa is used as an anti-pyretic and analgesic and is one of the essential components of Chinese Traditional Medicines used in cancer treatment. Although the leaf, root and fruit of Forsythia suspensa exhibit various pharmacological effects, their anti-cancer effectiveness remains to be elucidated. In the present study, the anti-proliferative effects of ethanolic extracts of leaf, root and fruit of Forsythia suspensa on esophageal carcinoma cells were examined. The results demonstrated that the extract of the root rather than that of the leaf or fruit produced the most marked arrest of cell growth. The present study was the first, to the best of our knowledge, to demonstrate which part of Forsythia suspensa is the most potent inducer of apoptosis in esophageal carcinoma cells. Of note, the leaf of Forsythia suspensa is commonly used for the preparation of tea in China (27) and the fruit is used for the preparation of certain oils, although these are not used for medicinal purposes (28). Previous studies have demonstrated that ethanolic extracts of Forsythia suspensa fruit have significant inhibitory effects against murine hepatocellular carcinoma cells (H22), human hematology cells (SMMC-7721), intestinal cancer cells (LOVo) and gastric carcinoma cells (BGC-823) $(8,9)$. The present study revealed that FSEER inhibited the proliferation of esophageal carcinoma TE-13 cells by inducing apoptosis.

A time- and dose-dependent investigation was conducted over $72 \mathrm{~h}$, with assays performed at 24,48 and $72 \mathrm{~h}$, using human TE-13 cells treated with $0.25-1.0 \mathrm{mg} / \mathrm{ml} \mathrm{FSEER.}$ Significant growth inhibition of the TE-13 cells was observed over the entire period of the experiment compared with control cells. Morphological and flow cytometric analyses of the FSEER-treated cells demonstrated an increase in apoptotic cells, suggesting that apoptosis is important in the growth inhibitory effects of FSEER.

The activation of caspase in apoptosis occurs via two distinct pathways. Caspase 3 activation is involved in two apoptotic signaling cascades as a final apoptotic executioner. In the present study, caspase- 3 and caspase- 9 , but not caspase- 8 , were activated by FSEER in the TE-13 cells, indicating that apoptosis was induced by FSEER through the intrinsic apoptotic pathway. This mechanism was similar to the role of certain chemotherapeutics on cancer cells, including paclitaxel and camptothecin $(29,30)$, which suggested that certain compounds with anti-tumor activity were present in FSEER. The quantity of mitochondrial Cyt- $c$ released into the cytoplasm is a signaling event in the intrinsic apoptotic activation pathway (31). The release of Cyt- $c$ from the mitochondria into the cytoplasm supports the activation of the intrinsic apoptotic pathway. Of note, in the present study, downstream events of caspase-3, including PARP cleavage, were detected $48 \mathrm{~h}$ after treatment, while Cyt- $c$ was observed to increase in the cytoplasm following FSEER treatment. In addition, mitochondrial outer membrane permeabilization and disruption of the MMP are independent triggers of the mitochondrial cell death cascade, resulting in the release of Cyt- $c$ from the intermembrane space of the mitochondria into the cytoplasm (32). The present study demonstrated that treatment of TE-13 cells with FSREE caused rapid depolarization of MMP, depicted by representative dot blots, which demonstrated that FSEER disrupted the MMP. This accounted for the Cyt- $c$ release from the mitochondria into the cytoplasm and confirmed that FSREE treatment induced TE-13 apoptosis via the mitochondrial pathway.

In addition, the Bcl-2 family, which consists of anti-apoptotic and proapoptotic proteins, are central regulators in the mitochondrial apoptotic pathway, acting to either suppress or promote the MMP changes required for release of Cyt- $c(33,34)$. The Bcl-2 family has been identified as a major regulator in controlling the mitochondrial apoptotic pathway (35). The present study demonstrated that the major anti-apoptotic proteins Bcl-2, Mcl-1 and Bcl-xL were downregulated, whereas the proapoptotic proteins Bad, Bax and Noxa were upregulated in the TE-13 cells following treatment with FSEER. Therefore, the release of Cyt- $c$ from the mitochondria into the cytoplasm induced by FSEER resulted from deregulation of Bcl2 family proteins.

Certain deregulated signaling pathways are involved in the occurrence and development of cancer, including esophageal carcinoma $(36,37)$. As important signaling molecules, JAK/STAT3 and ERK are deregulated in various types of cancer cell and can phosphorylate a series of transcription factors, which regulate gene expression and are important in cell proliferation, differentiation and survival. Furthermore, the Bcl2 family is regulated mainly by the JAK/STAT3 and ERK pathways in certain tumor cells $(38,39)$. Therefore, the present study investigated whether FSEER regulated the balance of Bcl 2 family proteins via these two signaling pathways. The results revealed that levels of p-JAK/STAT3 and pERK were significantly decreased by FSEER in vitro, which contributed to the decreases in survival rate and induction of apoptosis in TE-13 cells. Further investigation is required to analyze whether other signaling pathways are involved in FSEER.

In the present study, the effect of FSEER on the growth of TE-13 cells in vivo was also assessed. The results demonstrated that FSEER $(50 \mathrm{mg} / \mathrm{kg})$ decreased the cancer burden in xenograft mice. In addition, no toxicity to lung and liver was observed at the concentration of FSEER used, which suggested that FSEER may be a potential, safe anti-cancer drug.

In conclusion, the present study demonstrated that FSEER, as an anti-tumor agent, induced the apoptosis of esophageal carcinoma cells. However, important questions regarding the inhibitory effect of FSEER remain to be elucidated, including which active components of FSEER trigger the apoptosis of cancer cells. The compounds quercetin, phillyrin and pinoresinol, which are present in the fruit of Forsythia suspensa, have been shown to induce apoptosis in cancer cells $(8,40)$. However, the compounds in Forsythia suspensea root that exert an anti-tumor effect remain to be elucidated. Identification of these active components may assist in examining the physiological mechanisms and functions of Forsythia suspensa root.

\section{Acknowledgements}

This study was supported by the Natural Science Foundation of China (no. 81173611) and Chinese Medical Research of Hebei Province (no. 2011011. The authors would like to thank the New Drug Research and Development Co., Ltd, the North China 
Pharmaceutical Corporation, the China and Chinese Academy of Medical Sciences and Peking Union Medical College, China for their support.

\section{References}

1. Enzinger PC and Mayer RJ: Esophageal cancer. N Engl J Med 349: 2241-2252, 2003

2. Hou J, Liao LD, Xie YM, Zeng FM, Ji X, Chen B, Li YL, Zhu MX, Yang CX, Zhao Q, Chen T, Xu XE, Shen Jian, Guo MZ, Li EM and Xu LY: DACT2 is a candidate tumor suppressor and prognostic marker in esophageal squamous cell carcinoma. Cancer Prev Res 6: 791-800, 2013.

3. Wang LD, Zhou Q, Feng CW, Liu B, Qi YJ, Zhang YR, Gao SS, Fan ZM, Zhou Y, Yang CS, Wei JP and Zheng S: Intervention and follow-up on human esophageal precancerous lesions in Henan, northern China, a high-incidence area for esophageal cancer. Gan To Kagaku Ryoho 1: 159-172, 2002.

4. Mawhinney MR and Glasgow RE: Current treatment options for the management of esophageal cancer. Cancer Manag Res 4: 367-377, 2012.

5. Jemal A, Bray F, Center MM, Ferlay J, Ward E and Forman D: Global cancer statistics. CA cancer J Clin 61: 69-90, 2011.

6. Horie S: Chemoprevention of prostate cancer: soy isoflavones and curcumin. Korean J Urology 53: 665-672, 2012.

7. Sarkar FH, Li Y, Wang Z and Padhye S: Lesson learned from nature for the development of novel anti-cancer agents: implication of isoflavone, curcumin, and their synthetic analogs. Curr Pharm Des 16: 1801-1812, 2010.

8. Hu WJ, Qian XP, Tu YX, Shen ZT, Yu LX and Liu BR : Anti-tumor effect of extract of Fructus forsythiae alcohol. Nanjing Zhong Yi Yao Da Xue Xue Bao 23: 379-381, 2007 (In Chinese).

9. Liu GX, Wang TT, Hu WJ, Qian XP, Yu LX and Liu BR: Anticancer effect of ethanol extract of Fructus forsythiae on primary cancer cells isolated from ascites and pleural fluids. Shi Yong Lao Nian Bing Xue 23: 359-363, 2009 (In Chinese).

10. Wang CL, Yin HT and Liu BR: Effects of antiproliferation and radiosensitivity on PC-3 cell of prostate cancer induced by triterpenes component. Shandong Yi Xue Za Zhi 51: 25-27, 2011. (In Chinese).

11. Zhao LM, Shan BE, Du YY, Wang MX, Liu LH and Ren FZ: Periplocin from Cortex periplocae inhibits cell growth and down-regulates survivin and c-myc expression in colon cancer in vitro and in vivo via $\beta$-catenin/TCF signaling. Oncol Rep 24: 375-83, 2010.

12. Slee EA, Harte MT, Kluck RM, Wolf BB, Casiano CA, Newmeyer DD, Wang HG, Reed JC, Nicholson DW, Alnemri ES, Green DR and Martin SJ: Ordering the cytochrome c-initiated caspase cascade: hierarchical activation of caspases- $2,-3,-6,-7,-8$ and -10 in a caspase-9-dependent manner. J Biol Chem 144: 281-292, 1999.

13. Berg CP, Engels IH, Rothbart A, Lauber K, Renz A, Schlosser SF, Schulze-Osthoff K and Wesseborg S: Human mature red blood cells express caspase- 3 and caspase- 8 , but are devoid of mitochondrial regulators of apoptosis. Cell Death Differ 8: 1197-1206, 2001

14. Soldani C and Scovassi AI: Poly (ADP-ribose) polymerase-1 cleavage during apoptosis: an update. Apoptosis 7: 321-328, 2002.

15. Sánchez-Hidalgo M, Lee M, Lastra CA, Guerrero JM and Pachham G:-; Melatonin inhibits cell proliferation and induces caspase activation and apoptosis in human malignant lymphoid cell lines. J Pineal Res 53: 366-373, 2012.

16. Marsden VS, O'Connor L, O'Reilly LA, Silke J, Metcalf D, Ekert PG, Huang DC, Cecconi F, Kuida K, Tomaselli KJ, Roy S, Nicholson DW, Vaux DL, Bouillet P, Adams JM and Strasser A: Apoptosis initiated by $\mathrm{Bcl}-2$-regulated caspase activation independently of the cytochrome c/Apaf-1/caspase-9 apoptosis. Nature 419: 634-637, 2002.

17. Gross A, McDonnell JM and Korsmeyer SJ: Bcl-2 family members and the mitochondria in apoptosis. Genes Dev 13: 1899-1911, 1999.

18. Danial NN: Bcl-2 family proteins: critical checkpoints of apoptotic cell death. Clin Cancer Res 13: 7254-7263, 2007.

19. Xiong H, Zhang ZG, Tian XQ, Sun DF, Liang QC, Zhang YJ, Lu R, Chen YX, and Fang JY: Inhibition of JAK1,2/STAT3 signaling induces apoptosis, cell cycle arrest, and reduces tumor cell invasion in colorectal cancer cells. Neoplasia 10: 287-297, 2008.
20. Kuo ML, Chuang SE, Lin MT and Yang SY: The involvement of PI3-KAkt-dependent up-regulation of Mcl-1 in the prevention of apoptosis of Hep3B cells by interleukin-6. Oncogene 20: 677-685, 2001.

21. Hsu H S, Huang P I, Chang Y L, Tzao C, Chen YW, Shih HC, Hung SC, Chen YC, Tseng LM and Chiou SH: Cucurbitacin I inhibits tumorigenic ability and enhances radiochemosensitivity in non-small cell lung cancer-derived CD133-positive cells. Cancer 117: 2970-2985, 2011.

22. Spets H, Strömberg T, Georgii-Hemming P, Siljason J, Nilsson K and Jernberg-Wiklund $\mathrm{H}$ : Expression of the bcl-2 family of pro- and anti-apoptotic genes in multiple myeloma and normal plasma cells: regulation during interleukin-6 (IL-6)-induced growth and survival. Eur J Haematol 69: 76-89, 2002.

23. Song L, Li Y, Sun Y and Shen B: Mcl-1 mediates cytokine deprivation induced apoptosis of human myeloma cell line XG-7. Chinese Med J (Engl) 115: 1241-1243, 2002.

24. Rahaman SO, Harbor PC, Chernova O, Barnett GH, Vogelbaum MA and Haque SJ: Inhibiton of constitutively active STAT3 suppresses proliferation and induces apoptosis in glioblastoma multiforme cells. Oncogene 21: 8404-8413, 2002.

25. Gao J, Tian J, Lv Y, Shi F, Kong F, Shi H and Zhao L: Leptin induces function activation of cyclooxygenase-2 through JAK2/STAT3, MAPK/ERK and PIK3/AKT pathways in human endometrial cancer cells. Cancer Sci 100: 389-395, 2009.

26. Beales IL and Ogunwobi OO: Microsomal prostaglandin E synthase-1 inhibition blocks proliferation and enhances apoptosis in oesophageal adenocarcinoma cells without affecting endothelial prostacyclin production. Int J Cancer 126: 2247-2255, 2010.

27. Kang H S, Lee J Y and Kim C J: Anti-inflammatory activity of arctigenin from Forsythiae fructus. J Ethnopharmacol 116: 305-312, 2008.

28. Jiao J, Gai Q Y, Wei F Y, Luo M, Wang W, Fu YJ and Zu YG: Biodiesel from Forsythia suspense [(Thunb.) Vahl (Oleaceae)] fruit oil. Bioresour Technol 143: 653-656, 2013.

29. Haldar S, Chintapalli J and Croce C M: Taxol induces bcl-2 phosphorylation and death of prostate cancer cells. Cancer Res 56: 1253-1255, 1996.

30. Han Z, Wei W, Dunaway S, Calabresi P, Sedivy J, Hendrickson EA, Balan KV, Pantazis P and Wyche JH: Role of p21 in apoptosis and senescence of human colon cancer cells treated with camptothecin. J Biol Chem 277: 17154-17160, 2002.

31. Green R and Reed JC: Mitochondria and apoptosis. Science 281: 1309-1312, 1998.

32. Strathmann J, Klimo K, Sauer SW, Okun JG, Prehn JH and Gerhäuser C: Xanthohumol-induced transient superoxide anion radical formation triggers cancer cells into apoptosis via a mitochondria-mediated mechanism. FASEB J 24: 2938-2950, 2010.

33. Luo X, Budihardjo I, Zou H, Slaughter C and Wang X: Bid: a $\mathrm{Bcl} 2$ interacting protein, mediates cytochrome c release from mitochondria in response to activation of cell surface death receptors. Cell 94: 481-490, 1998.

34. Jiang $X$ and Wang X: Cytochrome C-mediated apoptosis. Annu Rev Biochem 73: 87-106, 2004.

35. Kuwana T and Newmeyer DD: Bcl-2-family proteins and the role of mitochondria in apoptosis. Curr Opin Cell Biol 15: 691-699, 2003.

36. Nelson E A, Sharma S V, Settleman J and Frank DA: A chemical biology approach to developing STAT inhibitors: molecular strategies for accelerating clinical translation. Oncotarget 2: 518, 2011.

37. Wang Z, Zhu S, Shen M, Liu J, Wang M, Li C, Wang Y, Deng A and Mei Q: STAT3 is involved in esophageal carcinogenesis through regulation of Oct-1. Carcinogenesis 34: 678-688, 2013.

38. Sepúlveda P, Encabo A, Carbonell-Uberos F and Miñana MD: $\mathrm{Bcl} 2$ expression is mainly regulated by JAK/STAT3 pathway in human $\mathrm{CD}_{34}{ }^{+}$hematopoietic cells. Cell Death Differ 14: 378-380, 2006.

39. Boucher MJ, Morisset J, Vachon P H, Reed JC, Lainé J and Rivard N: MEK/ERK signaling pathway regulated the expression of Bcl-2, Bcl-XL, and Mcl-1 and promotes survival of human pancreatic cancer cells. J Biol Chem 79: 355-369, 2000.

40. Park CH, Chang JY, Hahm ER, Park S, Kim HK and Yang CH: Quercetin, a potent inhibitor against $\beta$-catenin/Tcf signaling in SW480 colon cancer cells. Biochem Biophys Res Commun 328: 227-234, 2005. 